\title{
Symposium-in-Print
}

\section{UVA II Exposure of Human Skin Results in Decreased Immunization Capacity, Increased Induction of Tolerance and a Unique Pattern of Epidermal Antigen-Presenting Cell Alteration}

\author{
Gordon J. LeVee', Lois Oberhelman', Tom Anderson',2, Hillel Koren ${ }^{3}$ and Kevin D. Cooper ${ }^{\star 1,2,4}$ \\ 'Departments of Dermatology, University of Michigan, Ann Arbor, MI, USA; \\ 'Veterans Affairs Medical Centers, Ann Arbor, MI and Cleveland, OH, USA; \\ ${ }^{3}$ Health Effects Research Lab, EPA, Chapel Hill, NC, USA and \\ ${ }^{4}$ Case Western Reserve University, University Hospitals of Cleveland, Cleveland, OH, USA
}

Received 10 April 1996; accepted 31 May 1996

\section{ABSTRACT}

The risks incurred from increased exposure to UVA II (320-340 nm) (i.e. during sunscreen use and extended outdoor exposure, tanning parlors) are not well understood. Therefore, we explored the effects of UVA II on skin immune responses in humans. After a single local exposure (4 minimum erythemal dose [MED]) using a xenon arc lamp filtered with a narrow bandpass filter (335 $\pm 5 \mathrm{~nm}$ full width at half maximum), individuals were contact-sensitized with dinitrochlorobenzene (DNCB) through a UVA II exposure site or through normal skin. UVA II induced a marked decrease in the magnitude of skin immune responses $(P<\mathbf{0 . 0 0 0 1})$. The UVA II group had only $29 \%$ successful sensitizations, as compared to $83 \%$ in the control group. The percentage of individuals who remained tolerant to DNCB after two sensitizations was $23.6 \%$ for the UVA II-exposed group, as compared to $3.8 \%$ in the controls $(P=0.006)$. UVA II also uniquely altered the type of antigen-presenting cells present in the epidermis. Human leukocyte antigen (HLA)-DR ${ }^{+}$cells in control epidermal cell suspensions (C-EC) comprised a single, homogeneous population of Langerhans cells (LC) with the phenotype: $C D 1 a^{\text {hi }} \mathbf{D R}^{\text {mid }}$ $\mathrm{CD11}^{-} \mathrm{CD36}^{-}(1.5 \pm \mathbf{0 . 3 \%}$ of EC). UVA II irradiation reduced the number of such $L C$ to $0.6 \pm 0.2 \%$ of $E C$. Although cells expressing the macrophage phenotype:

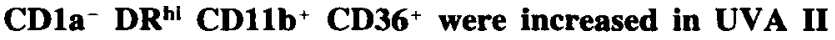
skin, relative to $\mathrm{C}$-EC, these comprised only $10.1 \pm 6.1 \%$ of the $\mathrm{DR}^{+}$cells, which is less than that after UVB exposure. Also distinct from UVB, a third population was found in UVA II-EC, which exhibited a novel phenotype:

\footnotetext{
*To whom correspondence should be addressed at: Department of Dermatology, Case Western Reserve University, University Hospitals of Cleveland, 11100 Euclid Avenue, Cleveland, OH 441065028, USA. Fax: 216-844-8993; e-mail: kdc@po.cwru.edu. (1) 1997 American Society for Photobiology 0031-8655/97 $\$ 5.00+0.00$
}

$\mathrm{CD1a}^{+} \mathrm{DR}^{+} \mathrm{CD36}^{+} \mathrm{CD11b}^{+}$; these comprised $11.1 \pm$ $6.9 \%$ of the DR ${ }^{+}$UVA II-EC.

In conclusion, despite the above differences in infiltrating $\mathrm{DR}^{+}$cells, both UVB and UVA II reduce the skin's ability to support contact sensitization, induce active suppression (tolerance) and induce a reduction in LC.

\section{INTRODUCTION}

In addition to the well-publicized increases in UVB due to ozone depletion, the potential for greater exposure to UVA is also increasing. The major deleterious effects of UVB wavelengths are well established. Clinically, these include the discomforts of sunburn, accelerated aging and wrinkling of chronically exposed skin, and the well-established relationships between UVB exposure and skin cancer. Immunologically, UVB exposure creates an immunosuppressed state in the host that increases susceptibility to skin cancers (1-4) and microbes (5-7), which appears due to alterations in presentation of the antigen to antigen-specific $\mathrm{T}$ lymphocytes $(2,8)$. These phenomena are nicely modeled by the contract sensitivity model of inducing antigen-specific delayed-type hypersensitivity, in which unresponsiveness and tolerance to antigens initially presented through UVB-exposed skin of both mice $(9,10)$ and humans $(11,12)$ is demonstrated to be due to $\mathrm{T}$ cells that block subsequent attempts to immunize through UV-irradiated skin (tolerance) $(8,13,14)$. Mechanistically UVB depletes epidermal Langerhans cells (LC) + from the epidermis $(15,16)$; however, the wavelength dependence of LC alteration and the wavelength dependence of contact sensitivity suppression are not the

†Abbreviations: APC, allophycocyanin; DNCB, dinitrochlorobenzene; DPCP, diphenylcyclopropenone; EC, epidermal cells; EMA, ethidium monoazide; FITC, fluorescein isothiocyanate; HLA, human leukocyte antigen; LC, Langerhans cells; MED, minimal erythemal dose; PBS, phosphate-buffered saline; UVA I, 340-400 $\mathrm{nm}$ radiation; UVA II, $320-340 \mathrm{~nm}$ radiation. 
same: UVA I (340-400 $\mathrm{nm})$ depletes LC in mice and humans (16-18) but does not induce distant immunosuppression, in contrast to UVB (19-21), and does not create a distant (systemic) immunological susceptibility to UV skin cancer (22). Whereas UVB induces epidermal infiltration of neutrophils (23) and immunosuppressive macrophages (2428), UVA $I$ is unable to induce leukocyte infiltration (29) and allows a rapid recovery of LC function (30). Other biological effects of long-wave UVA (UVA I) appear to be distinct in many ways from those of UVB (31). These effects include: 1000-fold less biological activity, less carcinogenic potential (32) and differential effects on lipid mediators (33$35)$, cytokine induction (36,27), DNA (38) and proteases $(39,40)$.

The effects of the UVA II $(320-340 \mathrm{~nm})$ wavelengths are less well studied and somewhat controversial (38). However, the frequency and intensity of exposure is increasing due to a number of factors. Many people are increasing their use of sunscreen products. This may result in an increase in their exposure to UVA, from 1) incomplete UVA protection by sunscreens designed to protect against UVB and from 2) longer exposure times allowed by the sunscreen before visible sunburn is apparent. Others increase their exposure to UVA by frequenting tanning parlors where UVA II radiation is a major component of the output of the lamps used. Many sun-sensitive people do both, in search of a "safe" means of obtaining a cosmetically attractive "healthy tan." Furthermore, stratospheric ozone performs a filtering function on solar UVA II, albeit not to the same degree as to UVB and UVC, and ozone depletion may increase its irradiance (41).

The purpose of this study was to determine whether UVA II differs from UVB in its ability to suppress epicutaneous immunization with dinitrochlorobenzene (DNCB) through exposed skin of humans, to determine whether UVA II is able to induce tolerance to subsequent DNCB immunizations on normal skin, and to determine whether UVA II is able to induce the influx of $\mathrm{CD} 1 \mathrm{a}^{-} \mathrm{CD} 36^{+} \mathrm{DR}^{+}$epidermal macrophages such as those that infiltrate epidermis following UVB irradiation of human skin.

\section{MATERIALS AND METHODS}

Volunteers. Paid volunteers were recruited, were screened for skin type and health status, gave signed informed consent and were treated using Institutional Review Board approved procedures forms and protocols. Subjects were randomly assigned to control and to UVAirradiated groups. The selected volunteers were limited to skin types I, II or III, were free from chronic disease and were not currently using medication.

UVA II light source. Ultraviolet A II radiation was supplied by a $5000 \mathrm{~W}$ xenon arc lamp (Optical Radiation Corporation, Azusa, CA) mounted in a modified Kratos lamp housing fitted with an IR-absorbing $\mathrm{H}_{2} \mathrm{O}$ filter (Spectral Energy Corporation, Westwood, NJ), a UV-reflecting dichroic mirror $(\sim 270-520 \mathrm{~nm})$ and a narrow bandpass filter $(335 \mathrm{~nm}, 10 \pm 2 \mathrm{~nm}$ full width, half maximum) (Andover Corporation, Salem, NH). Lamp output was monitored before and after each exposure, using an International Light IL-435 phototherapy radiometer fitted with a UVA filter on an SED 1240 detector (International Light, Inc., Newburyport, MA). Spectral output of the narrow bandpass filters used was checked using a Kratos $250 \mathrm{~mm}$ grating monochromator (Spectral Energy Corporation, Westwood, $\mathrm{NJ}$ ), using an IL-770 radiometer fitted with an SED 400 detector, QNDS (broad spectrum) filter and W diffuser.
Ultraviolet B was provided by a bank of FS-20 sunlamps with output as previously described $(12,25,42)$.

The UVA II source stability was monitored with an IL-435 phototherapy radiometer fitted with an SED 240 detector fitted with a UVA filter and wide angle window. The UVB source was monitored with an IL-435 phototherapy radiometer fitted with an SED 240 detector fitted with a UVB filter and wide angle window.

Irradiation. The minimal erythemal dose (MED) for UVA II was determined for each volunteer to enable delivery of biologically equivalent doses of UVR. The MED were determined by giving each subject a sequence of four exposures of increasing intensities, 10 , 20,30 and $40 \mathrm{~J} / \mathrm{cm}^{2}$. Four MED of UVA II were subsequently administered to an area of $2.5 \mathrm{~cm}$ by $5 \mathrm{~cm}$ on the left buttock of each volunteer in the irradiated group.

Sensitization. On the third day after irradiation, a $12 \mathrm{~mm}$ Finn chamber containing $48 \mu \mathrm{L}(30 \mu \mathrm{g})$ of $0.0625 \%$ DNCB in acetone was placed on the irradiation site (left buttock). A similar chamber containing $48 \mu \mathrm{L}(22.5 \mu \mathrm{g})$ of $0.0469 \%$ diphenylcyclopropenone (DPCP) in acetone was placed on the unirradiated right buttock as a control for unimpaired immune response and as a control for distant suppression. An equal number of unirradiated control volunteers was also sensitized on similar sites. The chambers remained in place on the skin for $48 \mathrm{~h}(121)$.

Challenge. Two to three weeks after sensitization, the skin fold thickness of the challenge sites was measured with an engineers' spring-loaded micrometer (Mitutoyo Manufacturing, Tokyo) and Finn chambers containing reduced quantities of the sensitizing chemicals were applied to the inner upper arms of each volunteer and left in place for $6 \mathrm{~h}$, as modified from the method of Friedmann et al. (43). On the right arm, one chamber contained vehicle control and four contained increasing concentrations of DNCB $(3.125 \mu \mathrm{g}$, $6.126 \mu \mathrm{g}, 8.8 \mu \mathrm{g}$ and $12.5 \mu \mathrm{g}$ ). An additional four chambers containing the control chemical DPCP $(0.390 \mu \mathrm{g}, 0.781 \mu \mathrm{g}, 1.56 \mu \mathrm{g}$ and $3.125 \mu \mathrm{g}$ ) were placed on the left arm (12).

Two days later, the intensity of the hypersensitivity response was determined by again measuring the skin fold thickness of the challenge sites. The difference between the before challenge and after challenge measurements was expressed as increase in skin thickness in $\mathrm{mm}$. A visual evaluation of the response was also recorded using the National Allergic Contact Dermatitis Group (NACDG) scale (12).

Epidermal cell (EC) isolation. For evaluation of UVA II effects on epidermal antigen-presenting cell population density and surface antigen profile, volunteers were irradiated with 4 MED UVA II as described above. Three days following irradiation, UVA II-irradiated skin and unirradiated control skin samples were obtained from each volunteer by keratome biopsy and EC suspensions were prepared as previously described (42). Briefly, the epidermis was separated from the dermis by overnight incubation with Dispase ${ }^{\circledR}$ (Collaborative Research, Waltham, MA) and EC suspensions obtained by incubation for $10 \mathrm{~min}$ in $0.125 \%$ trypsin in phosphate-buffered saline (PBS). The action of the trypsin was stopped by transfer of the epidermis to PBS containing $20 \%$ fetal calf serum plus $0.05 \% \mathrm{DNa}$ se to remove DNA released from damaged cells. The tissues were gently agitated to disperse the EC and cell clumps were removed by filtration through 112 mesh NYTEX ${ }^{\otimes}$ nylon screen (42).

Staining to identify EC phenotypes. Aliquots of EC suspensions were preincubated for $30 \mathrm{~min}$ at $4^{\circ} \mathrm{C}$ with mouse IgG1, mouse IgG2 (Sigma) and normal human $\mathrm{AB}$ serum, at $20 \mu \mathrm{L}$ each per $10^{6}$ cells. The cells were then stained with specific antibodies directly conjugated to the fluorochromes (or to biotin in the case where the streptavidin allophycocyanin [APC] secondary fluorochrome was used) at $2 \mu \mathrm{g} / 10^{6}$ cells for $45 \mathrm{~min}$ at $4^{\circ} \mathrm{C}$, washed three times and the cells incubated with APC for $30 \mathrm{~min}$. After one wash, ethidium monoazide (EMA) was added to each sample (to identify nonviable cells), incubated under fluorescent lamps for $10 \mathrm{~min}(23,44)$, washed again and fixed in formaldehyde for flow cytometric analysis. Epidermal cell phenotypes were identified by four-color flow cytometry (42).

Viable EC (EMA negative) were selected based on low EMA intensity (lack of uptake of EMA by viable cells). The specific antibodies used for obtaining EC subpopulations were: $P E$ anti-human leukocyte antigen (HLA)-DR (Ig2a isotype) and PE anti-CD11b (IgGl isotype) both from Becton Dickenson, San Jose, CA. The PE anti-CDla (T6 RD1) from Coulter, Hialeah, FL; fluorescein isothio- 


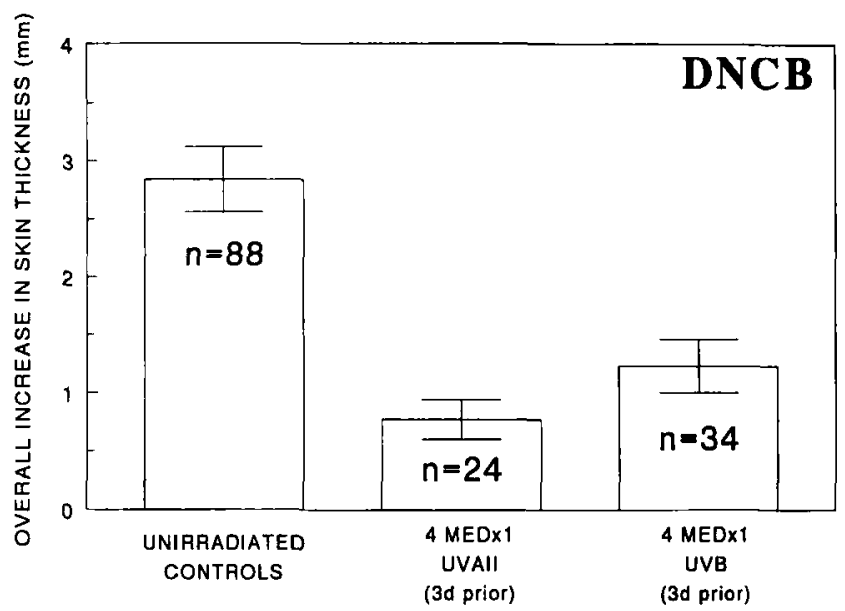

Figure 1. Four MED UVA II $(335 \pm 5 \mathrm{~nm})$ reduces the mean response to DNCB sensitization in humans to a level equal to that produced by a 4 MED UVB exposure. A single exposure of either UVA II or UVB given 3 days prior to sensitization significantly reduces the response to DNCB sensitization as measured by the mean increase in skin thickness (mm) at challenge ( $y$ axis). Unirradiated controls, mean $=0.284 \pm 0.28 \mathrm{~mm}, \mathrm{n}=88$; UVA II-irradiated, mean $=0.77 \pm 0.17 \mathrm{~mm}, \mathrm{n}=24$; and UVB-irradiated, mean $=1.23 \pm 0.23 \mathrm{~mm}, \mathrm{n}=34$. For UVA II-irradiated subjects $v s$ control subjects, $P=0.000014$; for UVA II-irradiated $v s$ UVBirradiated are not significantly different, $P=0.144$; for UVB-irradiated $v s$ control, $P=0.000113$.

cyanate (FITC) anti-Cdl1b (AMAC, Westbrook, ME), FITC antiCD la (OKT6), FITC anti-CD36 (OKM5) (both, Ortho, Raritan, NJ), and biotinylated CDIlc (Sigma, St. Louis, MO) were all of IgG1 isotype. Biotinylated anti-HLA-DR, with isotype IgG2a, was from Becton Dickenson. The HLA-DR ${ }^{+}$cells were selected from among the viable cells based upon intensity of APC staining. Displaying the HLA-DR ${ }^{+}$population of cells on histograms whose axes displayed the intensity of staining for a pair of the other antigens allowed identification of cell populations that were single positive, double positive or triple positive for the antigens being analyzed.

\section{RESULTS}

\section{Effects of UVA II radiation on human sensitization to DNCB}

Like UVB, a single 4 MED dose of UVA II, given 3 days prior to sensitization with DNCB, strongly suppresses the contact sensitivity response in humans, as measured by the mean increase in skin fold thickness (edema) in mm upon DNCB challenge (Fig. 1). The unirradiated control subjects were pooled from concurrent and historical controls for comparison to both the UVB and UVA II groups. The increase in mean thickness was $2.84 \pm 0.28 \mathrm{~mm}, \mathrm{n}=88$, for the unirradiated control group. The mean thickness increase for the UVA II-irradiated subjects was $0.775 \pm 0.17 \mathrm{~mm}, \mathrm{n}=$ 24 , a significant reduction $(P=0.000014)$ upon comparison to the unirradiated controls. As previously described (12), the mean increase in skin fold thickness for the UVB-irradiated subjects, $1.23 \pm 0.23 \mathrm{~mm}, \mathrm{n}=34$, was also significantly different from the controls, $P=0.00013$. The difference between the UVA II-irradiated group and the UVB group was not significant, $P=0.14$. Thus, at 4 MED, UVA II is as effective as UVB in inducing suppression of the contact hypersensitivity response to DNCB.

Because heterogeneity of the human population has raised

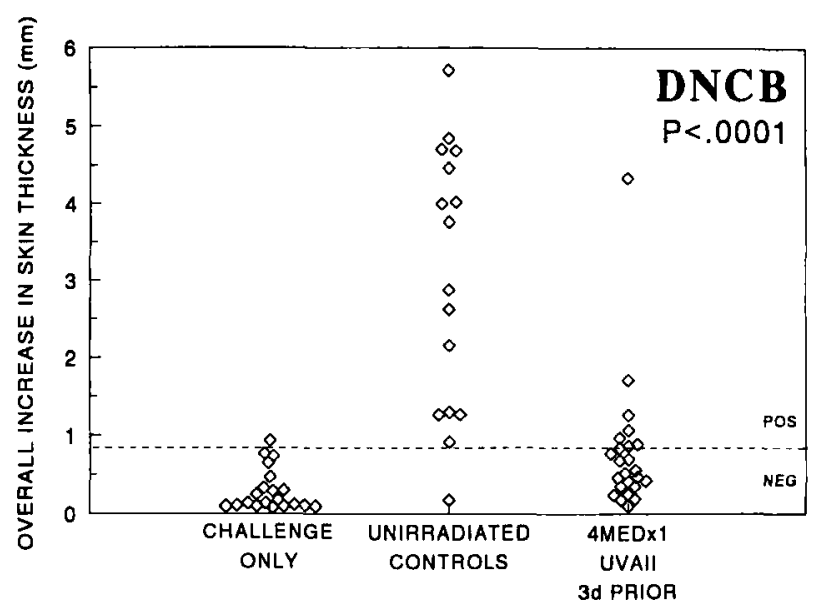

Figure 2. Scattergram reveals relatively homogenous reduction of DNCB response in human subjects sensitized on UVA II-exposed skin. A single exposure of UVA II $(335 \pm 5 \mathrm{~nm})$ given 3 days prior to sensitization significantly reduces the response to DNCB sensitization as measured by the mean increase in skin thickness ( $\mathrm{mm}$ ) at a challenge site ( $y$ axis). Challenge only, mean $=0.301 \pm 0.06$ $\mathrm{mm}, \mathrm{n}=20$; unirradiated controls, mean $=3.05 \pm 0.043 \mathrm{~mm}, \mathrm{n}=$ 16; UVA II-irradiated, mean $=0.775 \pm 017 \mathrm{~mm}, \mathrm{n}=24$. The response of the UVA II-irradiated subjects differed significantly from that of the unirradiated control subjects, $P<0.0001$.

the possibility of low and high susceptibility subsets that may correlate with skin cancer susceptibility (11), we also examined the data set for the presence of distinct groups, using a scatter plot (Fig. 2). The data for the unsensitized challenge group are also presented for comparison to the concurrently randomized positive control group (DNCB through normal skin) and the UVA II group. Whereas the mean irritant response to DNCB (challenge only) was 0.301 $\pm 0.006 \mathrm{~mm}, \mathbf{n}=20$, the positive control group demonstrated a mean response of $3.053 \pm 4.25 \mathrm{~mm}$, with $93.8 \%$ positive responses. By contrast, there were only $29.2 \%$ positive responses in the UVA II-irradiated, mean $=0.775 \pm 0.17$ $\mathrm{mm}, \mathrm{n}=24, P=0.02$. Although 2 of the 24 subjects exhibited a fully successful sensitization through UVA II-exposed skin, it is not clear whether this percentage reflects a distinct subgroup cluster.

\section{Effect of UVA II on an immunization through a site distant to the UVA II exposure}

Each volunteer was sensitized on a matching site on the opposite (right) buttock with a second, noncross-reacting sensitizer (DPCP) to test for distant (systemic) effects of the UV radiation exposures. As for DNCB, the response to DPCP sensitization was measured by the mean increase in skin thickness (mm) at challenge sites (Fig. 3). The DPCP is less efficient at sensitizing than is DNCB, sensitizing fewer than $75 \%$ of the unirradiated volunteers in the groups being presented, yet the DPCP response was frequently stronger than the DNCB response, often resulting in blisters at the challenge sites, which made measurement difficult. The challenge doses of DPCP were adjusted downward in some of the groups during the study, in an attempt to alleviate the blistering problem. Only the volunteers receiving the original dosages are included here, which explains the smaller numbers of volunteers shown. For the challenge only 


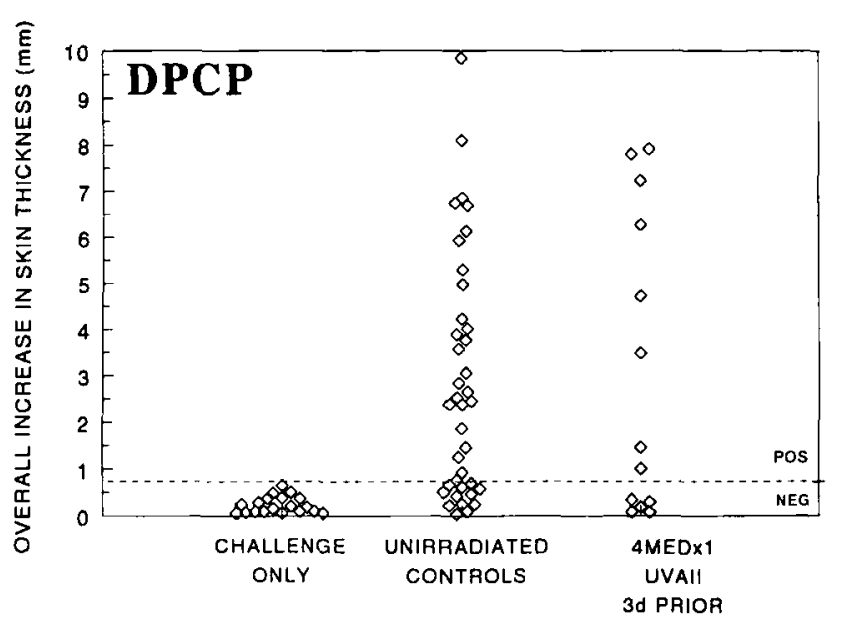

Figure 3. Scattergram of DPCP responses in human subjects sensitized distant from UVA II-exposed skin reveals distant immunosuppression. The DPCP sensitization on the buttock opposite to the DNCB sensitization was measured by the mean increase in skin thickness (mm) at a challenge site (shown on the y axis). Concurrently randomized challenge only negative controls, mean $=0.241$ $\pm 0.04 \mathrm{~mm}, \mathrm{n}=19$; unirradiated positive controls, mean $=2.54 \pm$ $0.36 \mathrm{~mm}, \mathrm{n}=36$; UVA II-irradiated subjects, mean $=3.15 \pm 0.89$ $\mathrm{mm}, \mathrm{n}=13$.

group, the mean skin fold thickness increase was $0.19 \pm$ $0.06 \mathrm{~mm}, \mathrm{n}=20$; for the unirradiated controls, the mean skin fold thickness increase was $2.88 \pm 0.41 \mathrm{~mm}, \mathrm{n}=38$. The mean skin fold thickness increase was $3.15 \pm 0.89 \mathrm{~mm}$ along the UVA II-irradiated volunteers $(n=13)$.

\section{Toleragenic effects of UVA II}

To determine whether sensitization on UVA II-exposed skin induces tolerance to subsequent exposure to DNCB, individuals who did not respond to challenge after the initial sensitization $(70.8 \%$ ) were resensitized on normal skin 2 weeks to 5 months later. Of these individuals, $23.8 \%$ were again unresponsive to DNCB sensitization, whereas, among unirradiated control individuals unresponsive to DNCB sensitization $(17 \%$ ), only $3.8 \%$ were still negative after resensitization on normal skin. This difference is significant, $P=$ 0.0006 .

\section{Effects of UVA II radiation on HLA DR ${ }^{+}$epidermal cell subsets}

Ethidium monoazide-negative viable cells were selected, and from them cells staining intensely with APC-HLA-DR were gated and selected for further analysis (Fig. 5a,e). Both the unirradiated EC (1) and the UVA II-irradiated EC (b) contained distinct populations of HLA-DR ${ }^{+}$cells. The EC stained with the isotype control contained only a negligible amount of background staining within the comparable areas (not shown).

The HLA-DR ${ }^{+}$cells in unirradiated control epidermis were homogeneously CD1 a ${ }^{\text {hi }}$ CD1 $1 c^{\text {lo }}$ (Fig. 5b), CD36- (Fig. 5c) and $\mathrm{CD} 1 \mathrm{~b}^{-}$(Fig. 5d). By contrast, UVA II-irradiated epidermis contained a heterogeneous population of $\mathrm{DR}^{+}$ cells. One population was represented by reduced LC $\left(\mathrm{CD} 1 \mathrm{a}^{\mathrm{hi}}, \mathrm{CD} 11 \mathrm{c}^{\mathrm{lo}}, \mathrm{CD}^{-} 6^{-} \mathrm{CD} 1 \mathrm{~b}^{-}\right.$cells in Fig. $5 \mathrm{f}$ circle $\mathrm{F}$; $5 \mathrm{~g}$ box $\mathrm{G} ; 5 \mathrm{~h}$ box $\mathrm{H}$ ). A second population could be iden-

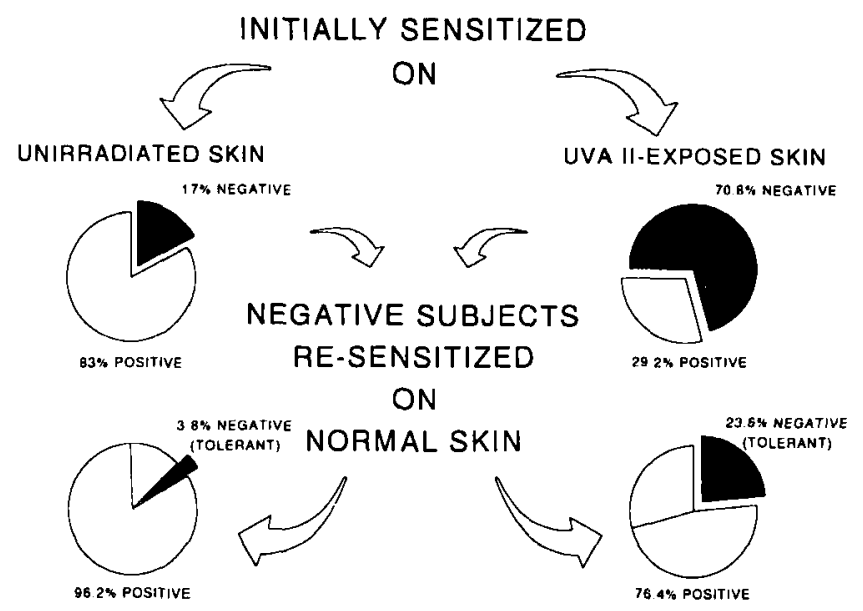

Figure 4. DNCB sensitization through a UVA II-exposure site causes decreased responsiveness and increased tolerance in $24 \%$ humans tested. The DNCB sensitization on UVA II-exposed skin resulted in $70.8 \%$ of individuals being unresponsive to challenge after the initial sensitization. These were then resensitized on normal skin. Of these individuals, $23.8 \%$ were again unresponsive to DNCB sensitization. By contrast, among individuals not receiving UVA II exposure yet unresponsive to initial DNCB sensitization (17\%), only $3.8 \%$ were still negative after resensitization on normal skin.

tified within an HLA-DR ${ }^{+} \mathrm{CD} 11 \mathrm{c}^{\text {hi }}$ non-LC population that was $\mathrm{CDla}^{-}$(Fig. 5f box I with $14.5 \%$ cells) relative to $0.0 \%$ cells that are $\mathrm{DR}^{+} \mathrm{CD} 1 \mathrm{cc}^{\mathrm{hi}} \mathrm{CD}^{+} \mathrm{a}^{-}$in control skin (Fig. 5b box $\mathrm{L}$ ). In contrast to $\mathrm{LC}$, which were $\mathrm{CD} 36^{-} \mathrm{CD} 11 \mathrm{~b}^{-}$, these $\mathrm{HLA}^{-\mathrm{DR}^{+}}$CD11 $\mathrm{c}^{\text {hi }}$ cells in UVA II-irradiated EC expressed macrophage markers and were thus $\mathrm{CD}^{+} 6^{+}$(Fig. $5 \mathrm{~g}$ circle $J$ ) and $\mathrm{CD}_{1} 1 \mathrm{~b}^{+}$(Fig. $5 \mathrm{~h}$ circle $\mathrm{K}$ ).

Data pertaining to the above cell populations (illustrated in Fig. 5) were pooled from multiple subjects (Table 1). The HLA-DR ${ }^{+}$portion of the viable EC was reduced by the irradiation from $1.5 \%$ of $\mathrm{EC}$ in the controls to $0.8 \%$ of $\mathrm{EC}$ in the UVA II-treated group $(P=0.005)$. Among the HLA$\mathrm{DR}^{+}$cells, the CD1a+ cells were reduced by UVA II from $90.1 \%$ of $\mathrm{DR}^{+}$cells in controls to $75.0 \%$ of the lowered $\mathrm{DR}^{+}$ cells within UVA II-EC. The CD1 a ${ }^{+}$LC expressing CD36 represented $0.8 \%$ of $\mathrm{LC}$ in control skin but rose to $11.1 \%$ of $\mathrm{DR}^{+}$cells in UVA II-expressed skin. Within the expanded $\mathrm{CD}^{-} \mathrm{a}^{-}$population, $\mathrm{CD}^{+} 6^{+}$monocytic/macrophagic cells rose from $<0.0 \%$ to $10.1 \%$, bringing the total $\mathrm{CD}^{+} 6^{+}$population to $18 \pm 3 \%$ of $\mathrm{DR}^{+}$UVA II-EC (not shown). Likewise, $\mathrm{CD} 1 \mathbf{l b}^{+}$monocytic/macrophagic cells increased from $3.2 \%$ in $\mathrm{DR}^{+}$cells in controls to $23.7 \%$ of $\mathrm{DR}^{+}$cells in the UVA II-treated group. The identities of the various subsets, as well as their quantitative relationships, are summarized in Fig. 6 as means of grouped data from multiple subjects. Each shared shading designation denotes a specific subset and whether it expresses the indicated marker (Fig. 6).

\section{DISCUSSION}

Ultraviolet A II has many biological activities in common with UVB. Ultraviolet A II is more biologically active than UVA I and highly relevant doses may be acquired during outdoor exposure as well as during tanning parlor exposure. Particularly high UVA II doses may occur when outdoor exposure times are increased due to the use of UVB-absorb- 


\section{Unirradiated Controls}
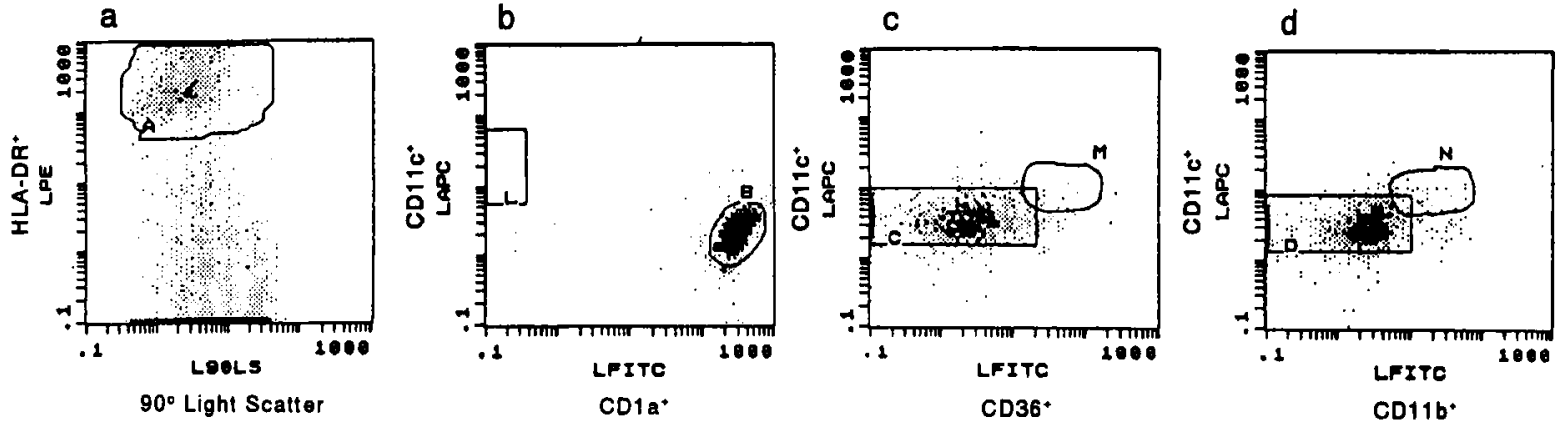

UVA-II Irradiated
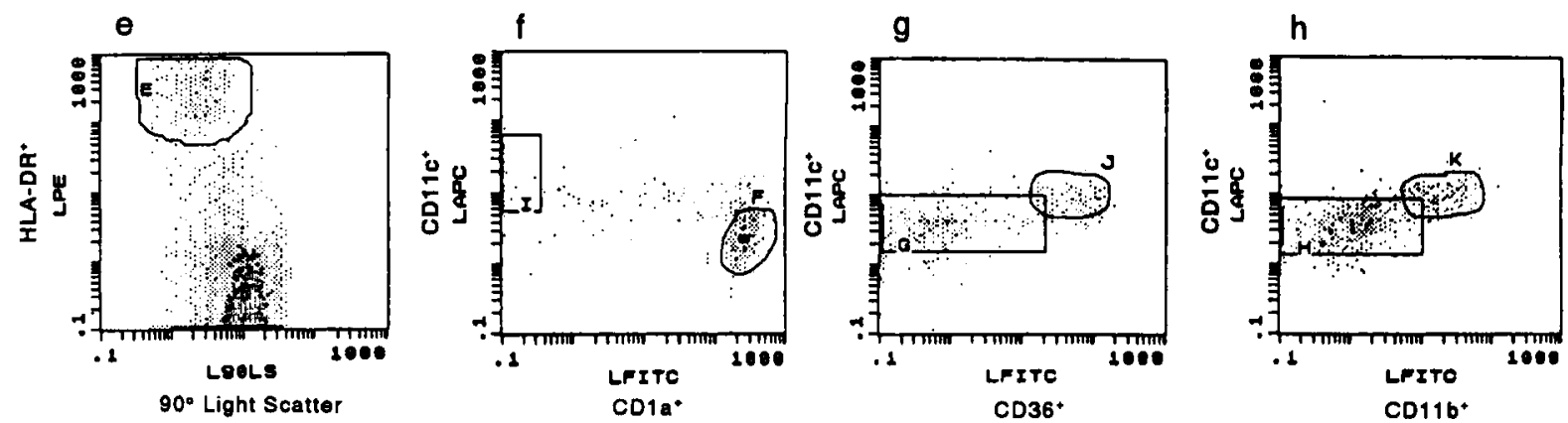

Figure 5. Ultraviolet A II irradiation induces a population of macrophage-like CD1a ${ }^{-}, C D^{2} 6^{+}, C D_{11} b^{+}$among the HLA-DR ${ }^{+}, C D_{11}{ }^{+}$ epidermal cells in human skin, similar to that induced by UVB. Four-color flow cytometric analysis shows contrasting patterns of cell phenotypes between UVA II-irradiated and unirradiated control skin. Frames a and e show selection of HLA-DR ${ }^{+}$cells in both groups. The $\mathrm{HLA} \mathrm{DR}^{+}$cells were then analyzed for CD11c, CDla, CD36 and CD11b. Frame b (unirradiated control skin) shows a distinct population of $\mathrm{CDla}^{+}$cells (gate $\mathrm{B}$ ) but no CDla ${ }^{-}$cells (gate L) among the CD1 $1 \mathrm{c}^{+}$cells. In UVA II-irradiated skin (frame f), with the same selection, $\mathrm{CD}_{1} \mathrm{a}^{+}$cells are reduced in number (gate $\mathrm{F}$ ) and there is a small, strongly CDla ${ }^{-}, \mathrm{CD} 1 \mathrm{c}^{\mathrm{hi}}$ population seen (gate I). There are insignificant numbers of $\mathrm{CD}^{+} 6^{+}$cells (frame c, gate $\mathrm{M}$ ) and $\mathrm{CD} 11 \mathrm{~b}^{+}$cells (frame $\mathrm{d}$, gate $\mathrm{N}$ ) in the unirradiated controls; however, the UVA II-irradiated cells clearly show the presence of both CD36 (frame $\mathrm{g}$, gate $\mathrm{J}$ ) and CD11b (frame h, gate $\mathrm{K}$ ), both of which are CD11 chi.

ing sunscreens. In addition, because UVA II intensity at the earth's surface is attenuated by stratospheric ozone, especially those wavelengths in the shorter, more energetic portion of this waveband, ozone depletion is predicted to result in increased biologic activity of UVA II wavelengths reaching the earth (45). The ability of UVA photons to alter the doseresponse relationship of UVB on EC (46), and the active role of UVA II in photocarcinogenesis (47-50), in immunologic alteration $(15,17,19,20,37,51,52)$ and in processes active in photoaging $(18,33,39,40,53-55)$ makes it impera- tive to understand the actions of UVA II in human skin in vivo.

We report here that UVA II has immunologic effects on human skin, which exhibit a distinctive pattern that shares some features with UVB exposure effects and some features with UVA I exposure effects. The human skin immunologic response to UVA II is similar to UVB in that there is: (a) a reduced ability to support contact sensitization; (b) a capacity to induce active suppression of DNCB responsiveness (tolerance); (c) a reduction in the number of LC (phenotype:

Table 1. UVA II* depletes CDla ${ }^{+} \mathrm{DR}^{+} \mathrm{LC}$ but concomitantly induces minor populations of $\mathrm{CD}^{*} \mathrm{a}^{-} \mathrm{DR}^{+}$cells expressing CD36 and/or CD11b

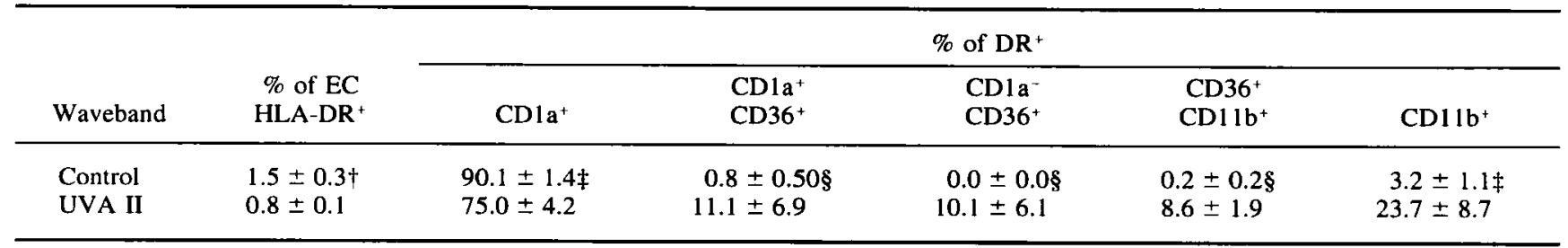

*All skin was tested 3 days after 4 MED UV irradiation.

$\dagger$ Percentage of total (viable) epidermal cells expressing the indicated phenotype (mean of $n=22, \pm S E M$ ).

$\ddagger$ Percentage of $\mathrm{DR}^{+}$cells expressing the indicated phenotype (mean of $n=10, \pm S E M$ ).

$\S$ Percentage of $\mathrm{DR}^{+}$cells expressing the indicated phenotype (mean of $n=4, \pm S E M$ ). 
Figure 6. Proportional relationships of $\mathrm{HLA}-\mathrm{DR}^{+}$subsets in epidermis from normal (a) and UVA-II (b)-exposed skin. Data expressed as \% of total EC for HLA-DR-expressing cells (top panels) or as \% of HLA$\mathrm{DR}^{+} \mathrm{EC}$ for cells expressing CDla, $\mathrm{CD} 36$ or $\mathrm{CD} 1 \mathrm{lb}$. From triple color analysis, cell populations are shown as distinct bar shadings to indicate subsets of the following phenotypes:

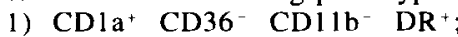

2) $\mathrm{CDIa}^{*} \mathrm{CD}^{+} 6^{+} \mathrm{CDIIb}^{-} \mathrm{DR}^{+}$:

3) $\mathrm{CDIa}^{-} \mathrm{CD}^{+} 6^{+} \mathrm{CD} 11 \mathrm{~b}^{+} \mathrm{DR}^{+}$;

4) $\mathrm{CD}_{\mathrm{a}} \mathrm{CD}_{3} 6^{-} \mathrm{CD}^{-} \mathrm{lb}^{+} \mathrm{DR}^{+}$

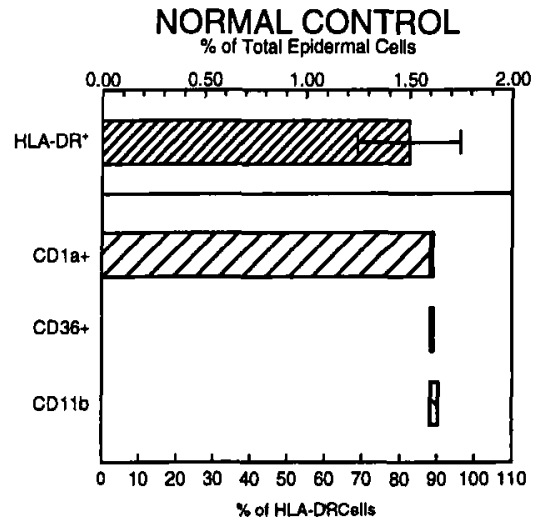

$\mathrm{CD}_{1} \mathrm{a}^{+} \mathrm{DR}^{+} \mathrm{CD}^{-} 6^{-} \mathrm{CD} 11 \mathrm{~b}^{-}$) and, (d) epidermal infiltration with cells of macrophagic phenotype $\left(\mathrm{CD} 1 \mathrm{a}^{-} \mathrm{DR}^{+} \mathrm{CD} 36^{+}\right.$ CD1 $1 b^{+}$). Ultraviolet A II differs from UVB in that it induces the appearance of a minor population of $\mathrm{LC}$ with a unique phenotype: $\mathrm{CD} 1 \mathrm{a}^{+} \mathrm{DR}^{+} \mathrm{CD} 36^{+} \mathrm{CD} 11 \mathrm{~b}^{+}$and results in a less potent depleting effect on $\mathrm{CDla}^{+} \mathrm{DR}^{+} \mathrm{LC}$ than does UVB.

It is not clear at this point whether the immunosuppressive effects of UVA II on contact sensitization induction in human subjects is due predominantly to the UVB-like effects or to the UVA-like effects. Ultraviolet A II is considered to contain both UVB and UVA I photons and the biologic activity of this waveband may be the result of a balanced or combinatorial effect of both types of photons, without an overwhelming dominance of one over the other $(38,56)$. Thus, study of this waveband may actually reflect the balance of processes that occur in response to the more intense mix of UVA I and UVB photons that occur in natural sunlight.

The dose of UVA II used in the current study, 4 MED, resulted in a highly suppressed immune response to DNCB in $90 \%$ of the subjects tested (Fig. 2). This effect is at least as, and possibly more suppressive than an equally erythemogenic single dose of UVB (Fig. 1), after which only about $60 \%$ of subjects are highly suppressed using fluorescent sunlamps (12).

Altered immunization in vivo is likely related to the changes observed in antigen-presenting cell composition of the epidermis after UVA II exposure. Ultraviolet A II clearly reduced LC density to levels comparable to similar doses of UVA and UVB. Ultraviolet A I and UVB both reduce LC density $(57,58)$, but UVA I results in only a very transient inhibition of LC functional activity, with extremely rapid recovery (30). Because LC that have newly repopulated the epidermis or in atopic dermatitis skin can doubly express CD1a and CD36 $(59,60)$ and normal human LC in the dermis can doubly express CDla and CD11b (42), it is possible that the novel population of $\mathrm{CDla}^{+}$cells expressing CD36 and $\mathrm{CD} 1 \mathrm{lb}$ in UVA II skin are repopulating immigrants from the dermis or blood (Fig. 4) (Table 1) (Fig. 6, double diagonal cross hashes).

With regard to macrophage infiltration (Table 1) (Fig. 6, double vertical horizontal cross hashes and single wide diagonal hashes) the degree of infiltration is markedly less after UVA II exposure $\left(\left[10.1 \% \mathrm{CD}^{+} 6^{+} \mathrm{CD} 1 \mathrm{a}^{-}\right.\right.$cells among $\mathrm{DR}^{+}$UVA II EC $] \times\left[0.8 \% \mathrm{DR}^{+}\right.$cells among total UVA II
$\mathrm{EC}]=0.08 \%$ of all UVA II EC that are macrophagic cells) (Table 1) than after UVB exposure (3-15\% of all UVB EC that are macrophagic cells) $(24,61)$ and in the same range as after UVA $I$ exposure ([33\% CD36 ${ }^{+}$among $\mathrm{DR}^{+}$UVA I $\mathrm{EC}] \times\left[0.3 \% \mathrm{DR}^{+}\right.$among total UVA $] \approx 0.1 \%$ of all UVA I EC that are macrophagic cells) (16). Whether these epidermal changes are reflected in the dermis, as they are after UVB (61), remains to be determined but may be a critical element dictating the outcome of immunization through UVA II-exposed skin.

In summary UVA II, the shorter wavelength, more energetic component of the UVA waveband, is clearly immunosuppressive. Its unique features of LC depletion with induction of LC of novel phenotype and without a high degree of macrophagic induction is more reminiscent of UVA I than UVB. In distinction to UVA I, however, UVA II induced tolerance to the contact sensitization, whereas murine UVA I studies have indicated an inability of UVA I to induce tolerance, despite LC depletion $(19,20)$. These findings indicate that conditions of increased UVA II exposure, such as during prolonged outdoor exposure under sunscreen, or tanning parlor exposure or exposure to stratospheric ozonedepleted solar radiation, will result in cutaneous immunosuppression to normally immunogenic agents introduced through the exposed skin.

We report here that a single erythemagenic exposure to UVA Il can reduce the immunization rate and induce tolerance to a potent immunogen such as DNCB. The appearance of complex mixtures of cells with antigen-presenting cell potential in the UVA II-exposed epidermis is further evidence that UVA II, although distinct in certain aspects from UVB, shares critical immunosuppressive activities with UVB.

Acknowledgements-We thank the Dermatology Treatment Center, in particular, Sandy Moore and J. Keedy, for all that they have done to help make these studies successful. We also thank Vashni Santee for her assistance in coordinating the preparation of this manuscript.

\section{REFERENCES}

1. Kripke, M. L. and M. S. Fisher (1976) Immunologic parameters for ultraviolet carcinogenesis. J. Natl. Cancer Inst. 57, 211-215.

2. Daynes, R. A., C. W. Spellman, J. G. Woodward and D. A. Stewart (1977) Studies into the transplantation biology of ultraviolet light-induced tumors. Transplantation 23, 343-348.

3. Strickland, P. T., D. Creasia and M. L. Kripke (1985) Enhancement of two-stage skin carcinogenesis by exposure of distant skin to UV radiation. J. Natl. Cancer Inst. 74, 1129-1134. 
4. Menzies, S. W., G. E. Greenoak, V. E. Reeve and C. H. Gallagher (1991) Ultraviolet radiation-induced murine tumors produced in the absence of ultraviolet radiation-induced systemic tumor immunosuppression. Cancer Res. 51, 2773-2779.

5. Jeevan, A., S. E. Ullrich, V. V. Dizon and M. L. Kripke (1991) Supernatants from ultraviolet-irradiated keratinocytes decrease the resistance and delayed-type hypersensitivity response to $M y$ cobacterium bovis bacillus calmette-guerin in mice and impair the phagocytic ability of macrophages. Photodermatol. Photoimmunol. Photomed. 8, 255-263.

6. Howie, S. E., M. Norval and J. P. Maingay (1986) Alterations in epidermal handling of HSV-1 antigens in vitro induced by in vivo exposure to UV-B light. Immunology 57, 225-230.

7. Denkins, Y., I. J. Fidler and M. L. Kripke (1989) Exposure of mice to UV-B radiation suppresses delayed hypersensitivity to Candida albicans. Photochem. Photobiol. 49, 615-619.

8. Kripke, M. L. and E. McClendon (1986) Studies on the role of antigen-presenting cells in the systemic suppression of contact hypersensitivity by UVB radiation. $J$. Immunol. 137, 443-447.

9. Elmets, C. A., P. R. Bergstresser, R. E. Tigelaar, P. J. Wood and J. W. Streilein (1983) Analysis of the mechanism of unresponsiveness produced by haptens painted on skin exposed to low dose ultraviolet radiation. J. Exp. Med. 158, 781-794.

10. Shimizu, T. and J. W. Streilein (1994) Local and systemic consequences of acute, low-dose ultraviolet $B$ radiation are mediated by different immune regulatory mechanisms. Eur. J. Immunol. 24, 1765-1770.

11. Yoshikawa, T., V. Rae, W. Bruins-Slot, J.-W. Van den Berg, J. R. Taylor and J. W. Streilein (1990) Susceptibility to effects of UVB radiation on induction of contact hypersensitivity as a risk factor for skin cancer in humans. J. Invest. Dermatol. 95, 530 536.

12. Cooper, K. D., L. Oberhelman, T. A. Hamilton, O. Baadsgaard, M. Terhune, G. LeVee, T. Anderson and H. Koren (1992) UV exposure reduces immunization rates and promotes tolerance to epicutaneous antigens in humans: relationship to dose, CDla$\mathrm{DR}^{+}$epidermal macrophage induction, and Langerhans cell depletion. Proc. Natl. Acad. Sci. USA 89, 8497-8501.

13. Elmets, C. A. (1983) In vivo low dose ultraviolet B (UV-B) irradiation induces $T$ suppressor cells to contact sensitizing agents. In The Effect of Ultraviolet Light on the Immune System. Anonymous, pp. 317-333. Johnson and Johnson, Inc.

14. Sauder, D. N., K. Tamaki, A. N. Moshell, H. Fujiwara and S. I. Katz (1981) Induction of tolerance to topically applied TNCB using TNP-conjugated ultraviolet light-irradiated epidermal cells. J. Immunol. 127, 261-265.

15. Aberer, G., G. Schuler, G. Stingl, H. Honigsmann and K. Wolff (1981) Ultraviolet light depletes surface markers of Langerhans cells. J. Invest. Dermatol. 76, 202-210.

16. Baadsgaard, O., H. C. Wulf, G. L. Wantzin and K. D. Cooper (1987) UVB and UVC, but not UVA, potently induce the appearance of $\mathrm{T}^{-}-\mathrm{DR}^{+}$antigen-presenting cells in human epidermis. J. Invest. Dermatol. 89, 113-118.

17. Mork, N. J., G. Gaudernack and L. R. Braathen (1987) Effect of UVA and PUVA on alloactivating and antigen-presenting capacity of human epidermal Langerhans cells. Photodermatology 4, 66-72.

18. Gilchrest, B. A., N. A. Soter, J. L. M. Hawk, R. M. Barr, A. K. Black, C. N. Hensby, A. I. Mallet, M. W. Greaves and J. A. Parrish (1983) Histologic changes associated with ultraviolet A-induced erythema in normal human skin. J. Am. Acad. Dermatol. 9, 213-219.

19. Morison, W. L., C. Bucana and M. L. Kripke (1984) Systemic suppression of contact hypersensitivity by UVB radiation is unrelated to the UVB-induced alterations in the morphology and number of Langerhans cells. Immunology 52, 299-306.

20. Noonan, F. P., C. Bucana, D. N. Sauder and E. C. DeFabo (1984) Mechanism of systemic immune suppression by UV irradiation in vivo. II. The UV effects on number and morphology of epidermal Langerhans cells and the UV-induced suppression of contact hypersensitivity have different wavelength dependencies. J. Immunol. 132, 2408-2416.

21. Noonan, F. P., E. C. DeFabo and M. L. Kripke (1981) Suppression of contact hypersensitivity by UV radiation and its re- lationship to UV-induced suppression of tumor immunity. Photochem. Photobiol. 34, 683-689.

22. Kelfkens, G., F. R. De Gruijl, H. van Weelden and J. C. Van Der Leun (1991) No influence of ventral UVA irradiation on subsequent tumourigenesis by dorsal UVB or UVA irradiation. Photochem. Photobiol. 53, 26S.

23. Cooper, K. D., N. Duraiswamy, C. Hammerberg, E. Allen, C. Kimbrough-Green, W. Dillon and D. Thomas (1993) Neutrophils, differentiated macrophages, and monocyte/macrophage antigen presenting cells infiltrate murine epidermis after $U V$ injury. J. Invest. Dermatol. 101, 155-163.

24. Cooper, K. D., G. R. Neises and S. I. Katz (1986) Antigenpresenting $\mathrm{OKM5}^{+}$melanophages appear in human epidermis after ultraviolet radiation. J. Invest. Dermatol. 86, 363-370.

25. Duraiswamy, N., Y. Tse, C. Hammerberg, S. Kang and K. D. Cooper (1994) Distinction of class II MHC ${ }^{+}$Langerhans celllike interstitial dendritic antigen-presenting cells in murine dermis from dermal macrophages. J. Invest. Dermatol. 103, 678683.

26. Baadsgaard, O., B. Salvo, A. Mannie, B. Dass, D. A. Fox and K. D. Cooper (1990) In vivo uitraviolet-exposed human epidermal cells activate $T$ suppressor cell pathways that involve CD4 ${ }^{+} \mathrm{CD} 45 \mathrm{RA}^{+}$suppressor-inducer T cells. J. Immunol. 145 , 2854-2861.

27. Hammerberg, C., N. Duraiswamy and K. D. Cooper (1994) Active induction of unresponsiveness (tolerance) to DNFB by in vivo ultraviolet-exposed epidermal cells is dependent upon infiltrating class II $\mathrm{MHC}^{+} \mathrm{CD} 11 \mathrm{~b}$ (bright) monocytic/macrophagic cells. J. Immunol. 153, 4915-4924.

28. Jun, B.-D., M. Y. L. Law, R. A. Daynes and L. K. Roberts (1989) Splenic contribution to the recovery of ATPase/la ${ }^{+}$epidermal cells in the skin of mice after exposure to ultraviolet radiation. Reg. Immunol. 2, 225-235.

29. Spellman, C. W., J. G. Woodward and R. A. Daynes (1977) Modification of immunological potential by ultraviolet radiation: I. Immune status of short-term UV-irradiated mice. Transplantation 24, 112-119.

30. Baadsgaard, O., S. Lisby, G. L. Wantzin, H. C. Wulf and K. D. Cooper (1989) Rapid recovery of Langerhans cell alloreactivity, without induction of autoreactivity, after in vivo ultraviolet $\mathrm{A}$. but not ultraviolet B exposure of human skin. J. Immunol. 142 , 4213-4218.

31. Mutzhas, M. F., V. von Arnim, H.-D. Hentschel, E. Volger and H. A. Stickl (1991) Effects of UV-A1-light on immune status in man. In Biological Responses to Ultraviolet A Radiation (Edited by F. Urbach), pp. 249-256. Valdenmar Publishing Company, Overland Park, KS.

32. Cole, C. A., P. D. Forbes and R. E. Davies (1986) An action spectrum for photocarcinogenesis. Photochem. Photobiol. 43, 275-284.

33. Hawk, J. L., A. K. Black, K. F. Jaenicke, R. M. Barr, N. A. Soter, A. I. Mallet, B. A. Gilchrest, C. N. Hensby, J. A. Parrish and M. W. Greaves (1983) Increased concentrations of arachidonic acid, prostaglandins E2, D2, and 6-oxo-F1a, and histamine in human skin following UVA irradiation. J. Invest. Dermatol. 80, 496-499.

34. Black, H. S., W. A. Lenger, J. Gerguis and J. I. Thornby (1985) Relation of antioxidants and level of dietary lipid to epidermal lipid peroxidation and ultraviolet carcinogenesis. Cancer Res. 45, 6254-6259.

35. Black, A. K., M. W. Greaves, C. N. Hensby and N. A. Plummer (1978) Increased prostaglandins E2 and F2a in human skin at 6 and $24 \mathrm{H}$ after ultraviolet B irradiation $(290-320 \mathrm{~nm}) . B r . J$. Clin. Pharmacol. 5, 431-436.

36. Kirnbauer, R., A. Kock, J. Krutmann, T. Schwarz, A. Urbanski and T. A. Luger (1989) Different effects of UVA and UVB irradiation on epidermal cell-IL 6 expression and release. $J . I n$ vest. Dermatol. 92, 459.

37. Kim, T.-Y., M. L. Kripke and S. E. Ullrich (1990) Immunosuppression by factors released from UV-irradiated epidermal cells: selective effects on the generation of contact and delayed hypersensitivity after exposure to UVA or UVB radiation. $J$. Invest. Dermatol. 94, 26-32.

38. Peak, M. J. and J. G. Peak (1992) Effects of solar ultraviolet 
photons on mammalian cell DNA. In Biologic Effects of Light (Edited by M. F. Holick and A. M. Kligman), pp. 417-424. Walter de Gruyter \& Co., Berlin.

39. Campbell, C., A. G. Quinn, B. Angus, P. M. Farr and J. L. Rees (1993) Wavelength specific patterns of p53 induction in human skin following exposure to UV radiation. Cancer Res 53, 26972699.

40. Herrmann, G., M. Wlaschek, T. S. Lange, K. Prenzel, G. Goerz and K. Scharffetter-Kockanek (1993) UVA irradiation stimulates the synthesis of various matrix-metalloproteinases (MMPs) in cultured human fibroblasts. Exp. Dermatol. 2, 92-97.

41. Frederick, J. E. and C. Erlick (1995) Trends and interannual variations in erythemal sunlight, 1978-1993. Photochem. Photobiol. 62, 476-484.

42. Meunier, L., A. Gonzalez-Ramos and K. D. Cooper (1993) Heterogeneous populations of class II $\mathrm{MHC}^{+}$cells in human dermal cell suspensions. Identification of a small subset responsible for potent dermal antigen-presenting cell activity with features analogous to Langerhans cells. J. Immunol. 151, 4067-4080.

43. Friedmann, P. S., C. Moss, S. Shuster and J. M. Simpson (1983) Quantitative relationships between sensitizing dose of DNCB and reactivity in normal subjects. Clin. Exp. Immunol. 53, 709715 .

44. Riedy, M. C., K. A. Muirhead, C. P. Jensen and C. C. Stewart (1991) Use of a photolabeling technique to identify nonviable cells in fixed homologous or heterologous cell populations. $C y$ tometry 12, 133-139.

45. Frederick, J. E., H. E. Snell and E. K. Haywood (1989) Solar ultraviolet radiation at the earth's surface. Photochem. Photobiol. 50, 443-450.

46. Dissanayake, N. S., G. E. Greenoak and R. S. Mason (1993) Effects of ultraviolet irradiation on human skin-derived epidermal cells in vitro. J. Cell. Physiol. 157, 119-127.

47. Staberg, B., H. C. Wulf, P. Klemp, T. Poulsen and H. Brodthagen (1983) The carcinogenic effect of UVA irradiation. $J$. Invest. Dermatol. 81, 517-519.

48. Gallagher, C. H., G. E. Greenoak, V. E. Reeve, P. J. Canfield, R. S. U. Baker and A. M. Bonin (1984) Ultraviolet carcinogenesis in the hairless mouse skin. Influence of the sunscreen 2-ethylhexyl-p-methoxycinnamate. Aust. J. Exp. Biol. Med. Sci. 62, 577-588.

49. Kelfkens, G., F. R. De Gruijl and J. C. Van Der Leun (1991) Tumorigenesis by short-wave ultraviolet $\mathrm{A}$ : papillomas versus squamous cell carcinomas. Carcinogenesis 12, 1377-1382.
50. Strickland, P. T. (1986) Photocarcinogenesis by near-ultraviolet (UVA) radiation in sencar mice. $J$. Invest. Dermatol. 87, 272 275.

51. Hersey, P., R. Noltorp and F. J. Wilkinson (1991) Effects of UV-A on natural killer (NK) cell activity, antigen presenting cells (APC) and induction of suppressor cells. Photochem. Photobiol. 53, 86S-87S.

52. Aubin, F. and M. L. Kripke (1991) Effects of ultraviolet A radiation on cutaneous immune cells. In Biological Responses to Ultraviolet A Radiation (Edited by F. Urbach), pp. 239-247. Valdenmar Publishing Company, Overland Park, KS.

53. Fuchs, J., M. E. Huflejt, L. M. Rothfuss, D. S. Wilson, G. Carcamo and L. Packer (1989) Acute effects of near ultraviolet and visible light on the cutaneous antioxidant defense system. Photochem. Photobiol. 50, 739-744.

54. Ronai, Z. A., E. Okin and I. B. Weinstein (1988) Ultraviolet light induces the expression of oncogenes in rat fibroblast and human keratinocyte cells. Oncogene 2, 201-204.

55. Petersen, M. J., C. Hansen and S. Craig (1992) Ultraviolet A irradiation stimulates collagenase production in cultured human fibroblasts. J. Invest. Dermatol. 99, 440-444.

56. Moan, J. and M. J. Peak (1989) Effects of UV radiation on cells. J. Photochem. Photobiol. B 4, 21-34.

57. Baadsgaard, O., K. D. Cooper, S. Lisby, H. C. Wulf and G. L. Wantzin (1987) Dose response and time course for induction of $\mathrm{T}-\mathrm{DR}^{+}$human epidermal antigen-presenting cells by in vivo ultraviolet A, B, and C irradiation. J. Am. Acad. Dermatol. 17, $792-800$

58. Aberer, W., G. Schuler, G. Stingl, H. Honigsmann and K. Wolff (1980) Effects of UV-light on epidermal Langerhans cells. $J$. Invest. Dermatol. 74, 458 .

59. Murphy, G. F., D. Messadi, E. Fonferko and W. W. Hancock (1986) Phenotypic transformation of macrophages to Langerhans cells in the skin. Am. J. Pathol. 123, 401-406.

60. Taylor, R. S., O. Baadsgaard, C. Hammerberg and K. D. Cooper (1991) Hyperstimulatory CD a ${ }^{+} \mathrm{CDIb}^{+} \mathrm{CD}^{2} 6^{+}$Langerhans cells are responsible for increased autologous $T$ lymphocyte reactivity to lesional epidermal cells of patients with atopic dermatitis. J. Immunol. 147 3794-3802.

61. Meunier, L., Z. Bata-Csorgo and K. D. Cooper (1995) In human dermis, UV induces expansion of a CD36 ${ }^{+} \mathrm{CD} 1 \mathrm{lb} \mathrm{b}^{+} \mathrm{CD} 1{ }^{-}$macrophage subset by infiltration and proliferation; $\mathrm{CD} 1^{+}$Langerhans-like dendritic antigen-presenting cells are concomitantly depleted. J. Invest. Dermatol. 105, 782-788. 